\title{
A Simple HPLC-DAD Method for the Analysis of Melamine in Protein Supplements: Validation Using the Accuracy Profiles
}

\author{
Domenico Montesano, Oriella Gennari, Carmen Festa, Franco Zollo, \\ Serenella Seccia, and Stefania Albrizio \\ Department of Pharmacy, University of Naples Federico II, Via D. Montesano 49, 80131 Naples, Italy \\ Correspondence should be addressed to Serenella Seccia; seccia@unina.it
}

Received 7 May 2013; Accepted 15 July 2013

Academic Editor: Pranav S. Shrivastav

Copyright (C) 2013 Domenico Montesano et al. This is an open access article distributed under the Creative Commons Attribution License, which permits unrestricted use, distribution, and reproduction in any medium, provided the original work is properly cited.

\begin{abstract}
The study presents a fully validated simple high-performance liquid chromatography method with diode array detection (HPLCDAD), able to accurately determine the melamine, fraudulently added, in protein supplements, commonly used from healthy adults to enhance exercise or sport performance. The validation strategy was intentionally oriented towards routine use and the reliability of the method rather than extreme performance. For this reason, validation by accuracy profile, including estimation of uncertainty, was chosen. This procedure, based on the concept of total error (bias + standard deviation), clearly showed that this method was able to determine melamine over the range of $0.05-3.0 \mathrm{mg} \mathrm{Kg}^{-1}$, selected by taking into account the maximum residue levels (MRLs) proposed by European legislation to distinguish between the unavoidable background presence of melamine and unacceptable adulteration. The accuracy profile procedure established that at least $95 \%$ of the future results obtained with the proposed method would be within the $\pm 15 \%$ acceptance limits of the validated HPLC-DAD method over the whole defined concentration range.
\end{abstract}

\section{Introduction}

Melamine (2,4,6-triamino-1,3,5-triazine) is commonly used as a raw material or additive in the manufacture of melamineformaldehyde plastics or can coatings for food contact materials. It can be found at low levels as a contaminant in a variety of foods due to the leaching from food contact materials [14].

For its nephrotoxicity [5-10] this chemical should not be intentionally added into foods or edible materials, in any circumstances. On the contrary, it is fraudulently added to food and/or feed ingredients to boost their total protein content and increase their market value. Such adulteration exploits a limitation of the most common nonspecific protein tests such as Kjeldahl method, which use total nitrogen as an indicator of protein content (melamine contains $66.6 \%$ of nitrogen by weight). In recent years the illegal addition of melamine to animal feedstuffs and infant milk formula caused illness and deaths of human infants and pet animals, who had taken the contaminated foods, primarily as a result of the accumulation of melamine-uric acid crystals in the urinary tract $[8,11-$ 15]. That is why various international health organizations have established regulations on melamine content over a wide variety of foods in order to safeguard public health $[9,16,17]$. In order to harmonize maximum residue levels (MRLs), set in many countries all over the world, European Food Safety Authority has proposed a legal maximum residue level (MRL) of $1.0 \mathrm{mg} / \mathrm{Kg}$ for infant foods and $2.5 \mathrm{mg} / \mathrm{Kg}$ for other foods to distinguish between the unavoidable background presence of melamine (from food contact materials, pesticide use, etc.) and unacceptable adulteration [18].

Protein supplements are largely used by athletes and physically active individuals to enhance nitrogen retention, to increase muscle mass, to prevent protein catabolism during prolonged exercise, and to promote muscle glycogen resynthesis following exercise. Therefore it is likely that the adulteration of this kind of supplements with melamine increases their apparent protein content.

In the scientific literature many methods have been proposed for the analysis of melamine in food and pet foodstuffs 
[19]. They are mainly based on common methodologies as gas chromatography (GC) and high-performance liquid chromatography (HPLC) in combination with different selective detection techniques [19-27]. More recent methods using electrochemical [28], surface-enhanced Raman spectroscopy (SERS) [29], infrared spectroscopy [30], colorimetric sensor based on polydiacetylene (PDA) liposomes [31], and quantum dots-based fluorescence method [32] have been published to detect melamine. All above mentioned methods are generally sensitive and accurate but they are not suitable for routine analysis because they are expensive and time consuming.

Based on these considerations, the first objective of the present study was to develop a rapid, simple, and accurate method for the quantitative determination of fraudulently added melamine to protein supplements, commonly used from healthy adults to enhance exercise or sport performance, to increase their total nitrogen concentration and consequently the calculated protein content. To authors' knowledge, only a method based on the use of micellar mobile phases for the chromatographic determination of melamine in dietetic supplements and validated following a traditional approach has been proposed [33].

Consequently, we selected an inexpensive HPLC-DAD technique due to its common availability also in laboratories, with limited financial resources, that have to perform regular monitoring of contaminants in food. The use of hydrophilic interaction liquid chromatography (HILIC) has been applied to melamine analysis to enhance its retention.

The second objective was to validate the method according to the strategy proposed by a Commission of the Société Française des Sciences et Techniques Pharmaceutiques (SFSTP) for the validation of quantitative analytical procedures in order to assess a routine food control technique [34-42]. The main advantage of this validation strategy, in comparison with other traditional validation approaches, is not only to take decision in accordance with predefined acceptance limits but also to control the risk associated with the future use of the method. This risk, which expresses the probability of measurements that are expected to fall outside the acceptance limits during routine analysis, gives analysts the guarantee that the method will be able to quantify with accuracy [37, 38, 43, 44], without applying interlaboratory studies [45].

\section{Materials and Methods}

2.1. Chemicals and Reagents. All chemicals and reagents were of analytical or HPLC grade and were purchased from SigmaAldrich (Milan, Italy). Melamine standard was obtained from Sigma-Aldrich (Milan, Italy).

The matrix was selected among dietetic supplements used in gyms; it contained milk and albumen proteins.

2.2. Instrumentation and Chromatographic Conditions. LC experiments were performed on a liquid chromatograph (Thermo Finnigan P4000) equipped with a 7125 Rheodyne injection valve (fitted with a $20 \mu \mathrm{L}$ loop). Detection was carried out by a Finnigan Spectra System UV 6000 LP photodiode-array detector, setting the wavelength at $220 \mathrm{~nm}$. Chromatograms were acquired using the ChromQuest version 4.2 software program (ThermoQuest, Milano, Italy). The analytical column was a Spherex $5 \mathrm{OH}($ diol, $250 \mathrm{~mm} \times$ $4.6 \mathrm{~mm}$ I.D., $5 \mu \mathrm{m}$ particle size) from Phenomenex (Torrance, CA, USA), with a Phenomenex $\mathrm{C}_{18}$ guard cartridge $(4 \times$ $8 \mathrm{~mm})$. The mobile phase was acetonitrile/acetate buffer $(\mathrm{pH}$ 5.0) $95: 5(\mathrm{v} / \mathrm{v})$. The flow rate was $1.0 \mathrm{~mL} / \mathrm{min}$.

2.3. Method Validation with Accuracy Profile. The objective of a quantitative analytical method is to be able to quantify as accurately as possible the solute of interest in its matrix. The difference between the result and the unknown true value of the sample (total error) must be lower than a predefined acceptance limit, which was fixed to $\pm 15 \%[46,47]$. The validation process is then to give guarantees that each of the future results that will be generated by the method will remain close enough to the true value. The proportion of measurements inside the acceptance limit must be larger than a given $\beta$-expectation tolerance interval fixed at $95 \%$. This means that the method can be considered as validated if the analyst can guarantee that, at least, $95 \%$ of measurements will fall within $\pm 15 \%$ of the actual value of the sample. The method validation was performed in accordance with the guidelines of the French Society of Pharmaceutical Sciences and Techniques (SFSTP) [35-41], using the total error approach $[36,48]$. Finally, the uncertainty of measurements derived from $\beta$-expectation tolerance intervals was estimated at each concentration level of the validation standards.

Because of the lack of specific regulatory references for melamine in dietary supplements, validation domains were established according to EFSA [18] and ranged from 0.05 up to $3.0 \mathrm{mg} \mathrm{Kg}^{-1}$. This allows us to cover the entire range to distinguish between the unavoidable presence of melamine and unacceptable adulteration. Selected calibration domains were similar to validation domains.

The statistical analysis was performed using Microsoft Excel 2003.

2.4. Experimental Designs. Validation and calibration designs both consisted in 3 days $(k=3), 3$ replicates $(n=3)$, and 3 levels $(m=3)$ of concentration. Altogether the number of trials was 27. These values were selected as a good compromise between the total number of analyses that can be achieved over one day and the cost of the validation study. Validation and calibration measurements were collected on the same days.

For calibration standards, a stock solution of melamine was prepared in methanol at $1.0 \mathrm{mg} / \mathrm{mL}$ and stored at $4^{\circ} \mathrm{C}$. Three solutions were obtained by diluting appropriate amounts of stock solution with the chromatographic mobile phase (acetonitrile/acetate buffer $\mathrm{pH} 5.0,95: 5(\mathrm{v} / \mathrm{v})$ ) to the final concentration levels of $0.05,1.5$, and $3.0 \mu \mathrm{g} \mathrm{mL}^{-1}$.

In order to validate the method following the "total error" approach, validation samples were obtained by spiking, as blank matrix, a dietary supplement, found to be negative for melamine. Spiked samples were prepared with convenient 
volumes of the intermediate stock solutions of melamine corresponding to three different spiking levels $(0.05,1.5$, and $3.0 \mathrm{mg} \mathrm{Kg}^{-1}$ ).

For each concentration level an amount of $1.0 \mathrm{~g}$ dietary supplement matrix was spiked. Sample preparation procedure consisted in adding $10 \mathrm{~mL}$ of ethanol to accurately weighed $1.0 \mathrm{~g}$ of matrix into a glass centrifuge tube. The tube was vortexed for $1 \mathrm{~min}$ to disperse the sample and centrifugated at $5000 \mathrm{~g}$ for $10 \mathrm{~min}$ at room temperature. The supernatant was discarded. Next $10 \mathrm{~mL}$ of acetonitrile/water $90: 10(\mathrm{v} / \mathrm{v})$ was added to the tube, vortexed for $1 \mathrm{~min}$, and centrifuged at $5000 \mathrm{~g}$ for $20 \mathrm{~min}$ at room temperature. The supernatant was recovered and evaporated in a SpeedVac system at $35^{\circ} \mathrm{C}$. The dried extract was then reconstituted with $1 \mathrm{~mL}$ of the chromatographic mobile phase.

\section{Results and Discussions}

3.1. HPLC Method. Melamine is a polar compound with high water solubility and never remains on the reverse stationary phase in HPLC. Recently, methods related to hydrophilic interaction liquid chromatography (HILIC) have been developed and applied to melamine analysis to enhance its retention and facilitate its separation [19, 24, 49-58]. HILIC is now clearly established as an important chromatographic technique for the retention and separation of polar and hydrophilic compounds. Although it has been accepted that partitioning is the main retention mechanism, secondary interactions (such as dipole-dipole and ion-exchange) can play an important role in the separation, leading to changes in selectivity. The retention mechanism in HILIC is due to the fact that complex interactions occur between the polar analyte, solvent molecules of the mobile phase, the polar stationary phase, and residual silanol on silica gel. For this reason the HILIC columns can retain polar compounds that are not retained by RP chromatography.

Based on these considerations a Spherex $5 \mathrm{OH}$ diol phase was chosen. The mobile phase was acetonitrile/acetate buffer $(\mathrm{pH} 5.0)$ 95:5 (v/v). The $\mathrm{pH}$ value was selected at 5.0 in order to have a good absorption spectrum for melamine and, at same time, to preserve the stability of the diol phase. Taking into account the absorption spectra and the literature [53], detection of melamine was carried out at $220 \mathrm{~nm}$.

\subsection{Method Validation}

3.2.1. Selectivity. Detection selectivity was assessed by the constancy of retention time of melamine and by monitoring the UV spectrum during the different analyses. The absence of interferences was checked on dietary supplement extract. No interferences were observed from this extract at the retention times of melamine, indicating that the proposed extraction procedure is effective, selective, and suitable for the determination of the target analyte (Figure 1).

3.2.2. Linearity. The linearity of the analytical procedure [59] was evaluated in the concentration range $0.05,1.5$, and

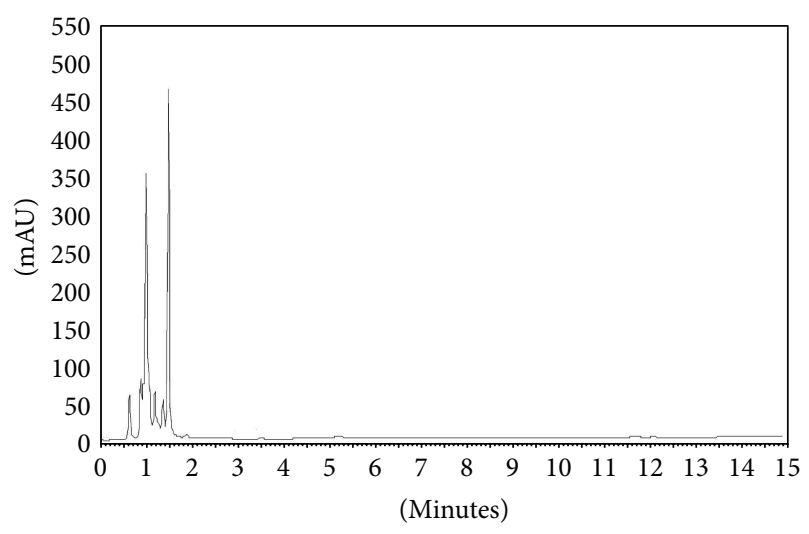

(a)

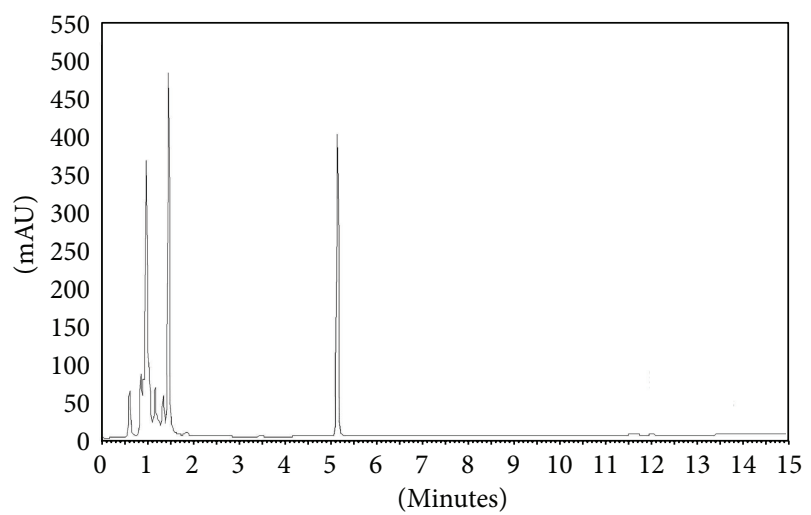

(b)

FIGURE 1: HPLC-DAD chromatogram (a) a blank dietary supplement and (b) of melamine $(4.20 \mathrm{~min})$ in validation sample (dietary supplement) spiked at $1.5 \mathrm{mg} / \mathrm{Kg}$.

$3.0 \mu \mathrm{g} \mathrm{mL} \mathrm{m}^{-1}$, selected depending on melamine levels established from EFSA to distinguish between the unavoidable background presence of melamine (from food contact materials, pesticide use, etc.) and unacceptable adulteration [18]. The calibration curve was calculated using ordinary leastsquare linear regression. The data are shown in Table 1 . The linearity was expressed by the coefficient of determination $\left(r^{2}\right)$. The relationship was linear as the $r^{2}$ value was equal to 0.9999 and the equation was close to $y=x$.

3.2.3. Trueness, Precision, Accuracy, and Uncertainty Assessment. The concentrations of the validation samples were back-calculated and were used to determine the relative bias, the repeatability, the intermediate precision, and the $\beta$ expectation tolerance intervals at the $95 \%$ probability level.

Trueness and precision give information, respectively, on systematic and random errors of the method. From data shown in Table 1, it can be concluded that trueness of the method was excellent, since the relative bias (\%) at each concentration level $[36,40]$ was less than $1.7 \%$, with good recoveries values demonstrating the high extraction efficiency of the method, and that a good precision, expressed as the relative standard deviations (RSD\%) for repeatability and 
TABLE 1: Accuracy profile validation results for melamine in dietary supplements.

\begin{tabular}{|c|c|c|}
\hline $\begin{array}{l}\text { Linearity } \\
(k=3, m=3, n=3)\end{array}$ & & \\
\hline Range $\left(\mu \mathrm{g} \mathrm{mL}^{-1}\right)$ & $0.05-3.0$ & \\
\hline Slope & 0.9659 & \\
\hline Intercept & 0.0081 & \\
\hline$r^{2}$ & 0.9999 & \\
\hline $\begin{array}{l}\text { Trueness }\left(\mathrm{mg} \mathrm{kg}^{-1}\right) \\
(k=3, m=3, n=3)\end{array}$ & Relative bias (\%) & Recovery (\%) \\
\hline 0.05 & -1.4 & 98.6 \\
\hline 1.5 & -0.6 & 99.4 \\
\hline 3.0 & -1.7 & 98.3 \\
\hline $\begin{array}{l}\text { Precision }\left(\mathrm{mg} \mathrm{kg}^{-1}\right) \\
(k=3, m=3, n=3) \\
\end{array}$ & Repeatability (RSD \%) & Intermediate precision (RSD \%) \\
\hline 0.05 & 2.1 & 2.2 \\
\hline 1.5 & 2.3 & 2.7 \\
\hline 3.0 & 2.0 & 2.3 \\
\hline $\begin{array}{l}\text { Accuracy }\left(\mathrm{mg} \mathrm{kg}^{-1}\right) \\
(k=3, m=3, n=3)\end{array}$ & & $\beta$-expectation tolerance limits (\%) \\
\hline 0.05 & & {$[-7.5 ; 4.7]$} \\
\hline 1.5 & & {$[-9.2 ; 7.9]$} \\
\hline 3.0 & & {$[-8.9 ; 5.5]$} \\
\hline $\begin{array}{l}\text { Uncertainty }\left(\mathrm{mg} \mathrm{kg}^{-1}\right) \\
(k=3, m=3, n=3)\end{array}$ & & Relative expanded uncertainty (\%) \\
\hline 0.05 & & 4.7 \\
\hline 1.5 & & 5.8 \\
\hline 3.0 & & 4.9 \\
\hline Limits of quantitation & & \\
\hline Lower LOQ & Upper LOQ & \\
\hline 0.05 & 3.0 & \\
\hline
\end{tabular}

$k$ : number of series; $m$ : number of amount levels; $n$ : number of replicates.

RSD: relative standard deviation.

intermediate precision $[38,42]$, was obtained not exceeding $5 \%$.

Accuracy takes into account the total error (sum of the systematic and random errors) of the test results [36, 38, 39]. It refers to the closeness of agreement between the test results and the acceptance reference value. As illustrated in Figure 2, the relative upper and lower $\beta$-expectation tolerance limits (\%) (reported in Table 1) did not exceed the acceptance limits of total error for each concentration level [38], confirming that the proposed method was accurate. Furthermore the risk of having future assay results exceeding $\pm 15 \%$ limits of the targeted amounts is strictly controlled.

Finally, the accuracy profile validation methodology allows, without any additional experiments, to obtain estimation of measurement uncertainty [35]. The expanded uncertainty was computed using a coverage factor of $k=2$ $[60,61]$, representing an interval around the results where the unknown true value can be observed with a confidence level of $95 \%$. Table 1 shows that relative expanded uncertainties were less than $6 \%$, which means that the unknown true value is located at a maximum of $\pm 6 \%$ around the measured result with a confidence of $95 \%$.

A lower limit of quantitation (LOQ), corresponding to the lowest limit of validation domain $\left(0.05 \mathrm{mg} \mathrm{Kg}^{-1}\right)$, may have been determined but, due to the actual level to establish the fraudulent addiction of melamine, it was unnecessary to explore lower concentration levels.

\section{Conclusions}

This paper described a simple, fast, and selective HPLCDAD method for the determination of melamine used to adulterate protein dietary supplements, based on HILIC technique. The method was validated by applying the accuracy profile approach. Compared to other traditional validation procedures, this strategy is a simple decision graphical tool based on the notion of the total error (bias and standard deviation) of the method allowing the immediate assessment of the method's validity. The accuracy profile of the proposed HPLC-DAD method guarantees that the method can 


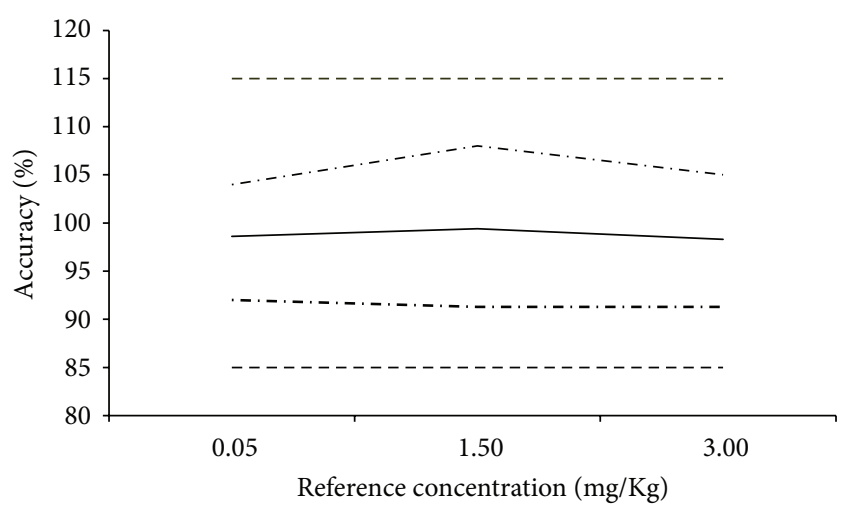

FIGURE 2: Accuracy profile obtained for the determination of melamine in dietary supplements using linear regression model. The continuous line is the recovery yield (\%), the dotted lines are the $\pm 15 \%$ acceptance limits, and the dashed lines are the upper and lower relative $95 \%$ expectation tolerance limits.

measure accurately melamine, for any protein supplement samples, over a range from 0.05 to $3.0 \mathrm{mg} \mathrm{Kg}^{-1}$. Indeed, the usefulness, practicability, and accessibility of this approach simplify the in-house single laboratory validation, allowing not only to evaluate its own performance but also to assess the uncertainty of measurements without applying interlaboratory studies.

\section{References}

[1] E. L. Bradley, V. Boughtflower, T. L. Smith, D. R. Speck, and L. Castle, "Survey of the migration of melamine and formaldehyde from melamine food contact articles available on the UK market," Food Additives and Contaminants, vol. 22, no. 6, pp. 597-606, 2005.

[2] K. H. Lund and J. H. Petersen, "Migration of formaldehyde and melamine monomers from kitchen- and tableware made of melamine plastic," Food Additives and Contaminants, vol. 23, no. 9, pp. 948-955, 2006.

[3] C.-Y. Chien, C.-F. Wu, C.-C. Liu et al., "High melamine migration in daily-use melamine-made tableware," Journal of Hazardous Materials, vol. 188, no. 1-3, pp. 350-356, 2011.

[4] Z. Chik, D. E. Mohamad Haron, E. D. Ahmad, H. Taha, and A. M. Mustafa, "Analysis of melamine migration from melamine food contact articles," Food Additives and Contaminants, vol. 28, no. 7, pp. 967-973, 2011.

[5] J. L. Dorne, D. R. Doerge, M. Vandenbroeck et al., "Recent advances in the risk assessment of melamine and cyanuric acid in animal feed," Toxicology and Applied Pharmacology, vol. 270, no. 3, pp. 218-229, 2012.

[6] R. Reimschuessel, E. R. Evans, C. B. Stine et al., "Renal crystal formation after combined or sequential oral administration of melamine and cyanuric acid," Food and Chemical Toxicology, vol. 48, no. 10, pp. 2898-2906, 2010.

[7] R. Reimschuessel and B. Puschner, "Melamine toxicity-stones vs. crystals," Journal of Medical Toxicology, vol. 6, no. 4, pp. 468469, 2010.

[8] US FDA (United States Federal and Drug Administration), Interim Safety and Risk Assessment of Melamine and Its Analogues in Food For Humans Silver Spring, United States Depart- ment of Health and Human Services, Food and Drug Administration Center for Food Safety and Applied Nutrition, 2008, http://www.fda.gov/ScienceResearch/SpecialTopics/PeerReviewofScientificInformationand Assessments/ucm155012.htm.

[9] WHO, Expert Meeting to Review Toxicological Aspects of Melamine and Cyanuric Acid by World Health Organization, 2008.

[10] WHO (World Health Organization), Toxicological and Health Aspects of Melamine and Cyanuric Acid, Report of a WHO Expert Meeting in Collaboration with FAO, 2009.

[11] R. L. M. Dobson, S. Motlagh, M. Quijano et al., "Identification and characterization of toxicity of contaminants in pet food leading to an outbreak of renal toxicity in cats and dogs," Toxicological Sciences, vol. 106, no. 1, pp. 251-262, 2008.

[12] R. P. Dalal and D. S. Goldfarb, "Melamine-related kidney stones and renal toxicity," Nature Reviews Nephrology, vol. 7, no. 5, pp. 267-274, 2011.

[13] E. Chan, S. Griffiths, and C. Chan, "Public-health risks of melamine in milk products," The Lancet, vol. 372, no. 9648, pp. 1444-1445, 2008.

[14] J. R. Ingelfinger, "Melamine and the global implications of food contamination," The New England Journal of Medicine, vol. 359, no. 26, pp. 2745-2748, 2008.

[15] W. H. Tolleson, "Intentional and unintentional contaminants in food and feed," in American Chemical Society, F. Al-Taher, L. S. Jackson, and J. W. DeVries, Eds., p. 55, 2009.

[16] EFSA (European Food Safety Authority), "Risks for public health due to the presences of melamine in infant milk and other milk products in China," EFSA Journal, vol. 807, pp. 1-10, 2008.

[17] U. S. FDA, Update: Interim a Safety and Risk Assessment of Melamine and Its Analogues in Food for Humans, United States Department of Health and Human Services, Food and Drug Administration Center for Food Safety and Applied Nutrition, 2008, http://www.fda.gov/Food/FoodborneIllnessContaminants/ChemicalContaminants/ucm164520.

[18] EFSA, "Scientific opinion on melamine in food and feed EFSA panel on contaminants in the food chain (CONTAM) and EFSA panel on food contact materials, enzymes, flavourings and processing aids (CEF)," EFSA Journal, vol. 8, no. 8, p. 1573, 2010.

[19] S. A. Tittlemier, "Methods for the analysis of melamine and related compounds in foods: a review," Food Additives and Contaminants A, vol. 27, no. 2, pp. 129-145, 2010.

[20] A. Arnold, T. N. Arrey, M. Karas, and M. Persike, "Fast quantitative determination of melamine and its derivatives by matrix-assisted laser desorption/ionization time-of-flight mass spectrometry," Rapid Communications in Mass Spectrometry, vol. 25, no. 19, pp. 2844-2850, 2011.

[21] E. Braekevelt, B. P.-Y. Lau, S. Feng, C. Ménard, and S. A. Tittlemier, "Determination of melamine, ammeline, ammelide and cyanuric acid in infant formula purchased in Canada by liquid chromatography-tandem mass spectrometry," Food Additives and Contaminants A, vol. 28, no. 6, pp. 698-704, 2011.

[22] Y.-Y. Chao, Y.-T. Wei, C.-T. Lee, H.-S. Kou, and Y.-L. Huang, "Membrane sampling with microdialysis coupled to HPLC/UV for on-line simultaneous determination of melamine and cyanuric acid in non-dairy coffee creamer," Analytical Sciences, vol. 27, no. 10, pp. 1025-1030, 2011.

[23] S. Goscinny, V. Hanot, J. F. Halbardier, J. Y. Michelet, and J. Van Loco, "Rapid analysis of melamine residue in milk, milk products, bakery goods and flour by ultra-performance liquid chromatography/tandem mass spectrometry: from food crisis to accreditation," Food Control, vol. 22, no. 2, pp. 226-230, 2011. 
[24] H. Sun, L. Wang, L. Ai, S. Liang, and H. Wu, "A sensitive and validated method for determination of melamine residue in liquid milk by reversed phase high-performance liquid chromatography with solid-phase extraction," Food Control, vol. 21, no. 5, pp. 686-691, 2010.

[25] F. Sun, W. Ma, L. Xu et al., "Analytical methods and recent developments in the detection of melamine," Trends in Analytical Chemistry, vol. 29, no. 11, pp. 1239-1249, 2010.

[26] H. Sun, X. Qin, X. Ge, and L. Wang, "Effective separation and sensitive determination of cyanuric acid, melamine and cyromazine in environmental water by reversed phase highperformance liquid chromatography," Environmental Technology, vol. 32, no. 3, pp. 317-323, 2011.

[27] Y. B. Zhong, L. J. Zhang, H. C. Zhang, J. X. Liu, and J. P. Wang, "Immunoaffinity-based solid phase extraction for the determination of melamine in animal-derived foods followed by LC," Chromatographia, vol. 73, no. 11-12, pp. 1211-1215, 2011.

[28] H. Zhu, S. Zhang, M. Li, Y. Shao, and Z. Zhu, "Electrochemical sensor for melamine based on its copper complex," Chemical Communications, vol. 46, no. 13, pp. 2259-2261, 2010.

[29] Y. Cheng and Y. Dong, "Screening melamine contaminant in eggs with portable surface-enhanced Raman spectroscopy based on gold nanosubstrate," Food Control, vol. 22, no. 5, pp. 685-689, 2011.

[30] R. M. Balabin and S. V. Smirnov, "Melamine detection by mid- and near-infrared (MIR/NIR) spectroscopy: a quick and sensitive method for dairy products analysis including liquid milk, infant formula, and milk powder," Talanta, vol. 85, no. 1 , pp. 562-568, 2011.

[31] J. Lee, E. Jeong Jeong, and J. Kim, "Selective and sensitive detection of melamine by intra/inter liposomal interaction of polydiacetylene liposomes," Chemical Communications, vol. 47, no. 1, pp. 358-360, 2011.

[32] M. Zhangay, H. Pingay, X. Caoa et al., "Rapid determination of melamine in milk using water-soluble CdTe quantum dots as fluorescence probes," Food Additives and Contaminants, vol. 29, no. 3, pp. 333-344, 2012.

[33] B. Beltrán-Martinavarro, J. Peris-Vicente, S. Marco-Peiró, J. Esteve-Romero, M. Rambla-Alegre, and S. Carda-Broch, "Use of micellar mobile phases for the chromatographic determination of melamine in dietetic supplements," Analyst, vol. 137, no. 1, pp. 269-274, 2012.

[34] P. Araujo, "Key aspects of analytical method validation and linearity evaluation," Journal of Chromatography B, vol. 877, no. 23, pp. 2224-2234, 2009.

[35] M. Feinberg, B. Boulanger, W. Dewé, and P. Hubert, "New advances in method validation and measurement uncertainty aimed at improving the quality of chemical data," Analytical and Bioanalytical Chemistry, vol. 380, no. 3, pp. 502-514, 2004.

[36] M. Feinberg, "Validation of analytical methods based on accuracy profiles," Journal of Chromatography A, vol. 1158, no. 1-2, pp. 174-183, 2007.

[37] P. Hubert, J. J. Nguyen-Huu, B. Boulanger et al., "Validation of quantitative analytical procedure, harmonization of approaches," S.T.P. Pharma Pratiques, vol. 13, no. 3, pp. 101-138, 2003.

[38] P. Hubert, J.-J. Nguyen-Huu, B. Boulanger et al., "Harmonization of strategies for the validation of quantitative analytical procedures: a SFSTP proposal-part I," Journal of Pharmaceutical and Biomedical Analysis, vol. 36, no. 3, pp. 579-586, 2004.

[39] P. Hubert, J.-J. Nguyen-Huu, B. Boulanger et al., "Harmonization of strategies for the validation of quantitative analytical procedures. A SFSTP proposal-part III," Journal of Pharmaceutical and Biomedical Analysis, vol. 45, no. 1, pp. 82-96, 2007.

[40] P. Hubert, J.-J. Nguyen-Huu, B. Boulanger et al., "Harmonization of strategies for the validation of quantitative analytical procedures: a SFSTP proposal. Part IV. Examples of application," Journal of Pharmaceutical and Biomedical Analysis, vol. 48, no. 3, pp. 760-771, 2008.

[41] ISO/IEC, General Requirements for the Competence of Testing and Calibration Laboratories, ISO, Geneva, Switzerland, 2005.

[42] E. Rozet, V. Wascotte, N. Lecouturier et al., "Improvement of the decision efficiency of the accuracy profile by means of a desirability function for analytical methods validation. Application to a diacetyl-monoxime colorimetric assay used for the determination of urea in transdermal iontophoretic extracts," Analytica Chimica Acta, vol. 591, no. 2, pp. 239-247, 2007.

[43] B. Boulanger, P. Chiap, W. Dewe, J. Crommen, and P. Hubert, "An analysis of the SFSTP guide on validation of chromatographic bioanalytical methods: progresses and limitations," Journal of Pharmaceutical and Biomedical Analysis, vol. 32, no. 4-5, pp. 753-765, 2003.

[44] R. Mee, "Estimation of the percentage of a normal distribution lying outside a specified interval," Communication in Statististics, vol. 17, no. 5, pp. 1465-1479, 1988.

[45] Analytical Methods Committee, "Uncertainty of measurement: implications of its use in analytical science," Analyst, vol. 120, no. 9, pp. 2303-2306, 1995.

[46] V. P. Shah, K. K. Midha, S. Dighe et al., "Analytical methods validation: bioavailability, bioequivalence and pharmacokinetics studies," International Journal of Pharmaceutics, vol. 82, no. 1-2, pp. 1-7, 1992.

[47] Food and Drug Administration, Guidance For Industry, Bioanalytical Methods Validation, US Food and Drug Administration, 2001.

[48] M. Feinberg and M. Laurentie, "A global approach to method validation and measurement uncertainty," Accreditation and Quality Assurance, vol. 11, no. 1-2, pp. 3-9, 2006.

[49] W. C. Andersen, S. B. Turnipseed, C. M. Karbiwnyk et al., "Determination and confirmation of melamine residues in catfish, trout, tilapia, salmon, and shrimp by liquid chromatography with tandem mass spectrometry," Journal of Agricultural and Food Chemistry, vol. 56, no. 12, pp. 4340-4347, 2008.

[50] R. L. Epstein, V. Randecker, P. Corrao, J. T. Keeton, and H. R. Cross, "Influence of heat and cure preservatives on residues of sulfamethazine, chloramphenicol, and cyromazine in muscle tissue," Journal of Agricultural and Food Chemistry, vol. 36, no. 5, pp. 1009-1012, 1988.

[51] D. N. Heller and C. B. Nochetto, "Simultaneous determination and confirmation of melamine and cyanuric acid in animal feed by zwitterionic hydrophilic interaction chromatography and tandem mass spectrometry," Rapid Communications in Mass Spectrometry, vol. 22, no. 22, pp. 3624-3632, 2008.

[52] M. Lin, "A review of traditional and novel detection techniques for melamine and its analogues in foods and animal feed," Frontiers of Chemical Engineering in China, vol. 3, no. 4, pp. 427435, 2009.

[53] R. Muñiz-Valencia, S. G. Ceballos-Magaña, D. RosalesMartinez et al., "Method development and validation for melamine and its derivatives in rice concentrates by liquid chromatography. Application to animal feed samples," Analytical and Bioanalytical Chemistry, vol. 392, no. 3, pp. 523-531, 2008. 
[54] T. Sugita, H. Ishiwata, K. Yoshihira, and A. Maekawa, "Determination of melamine and three hydrolytic products by liquid chromatography," Bulletin of Environmental Contamination and Toxicology, vol. 44, no. 4, pp. 567-571, 1990.

[55] P. Varelis and R. Jeskelis, "Preparation of $\left[{ }^{13} \mathrm{C} 3\right]$-melamine and $\left[\begin{array}{ll}{ }^{13} & \mathrm{C} 3\end{array}\right]$-cyanuric acid and their application to the analysis of melamine and cyanuric acid in meat and pet food using liquid chromatography-tandem mass spectrometry," Food Additives and Contaminants A, vol. 25, no. 10, pp. 1208-1215, 2008.

[56] Y. Wang, H. Gu, X. Lu, and G. Xu, "Development of hydrophilic interaction chromatographic hyphenated techniques and their applications," Se Pu, vol. 26, no. 6, pp. 752-754, 2008.

[57] R. Wei, R. Wang, Q. Zeng, M. Chen, and T. Liu, "Highperformance liquid chromatographic method for the determination of cyromazine and melamine residues in milk and pork," Journal of Chromatographic Science, vol. 47, no. 7, pp. 581-584, 2009.

[58] X.-L. Zheng, B.-S. Yu, K.-X. Li, and Y.-N. Dai, "Determination of melamine in dairy products by HILIC-UV with NH2 column," Food Control, vol. 23, no. 1, pp. 245-250, 2012.

[59] S. Huet, E. Jolivet, and A. Messean, Regression Non Lineare, INRA, Paris, France, 1992.

[60] Eurachem/Citac Guide, Quantifying the Uncertainty in Analytical Measurement, 2nd edition, 2000.

[61] JCGM 100:2008, Evaluation of measurement data-Guide to the expression of uncertainty in measurement (GUM), http://www.bipm.org/utils/common/documents/jcgm/JCGM_ 100_2008_E.pdf, 2008. 

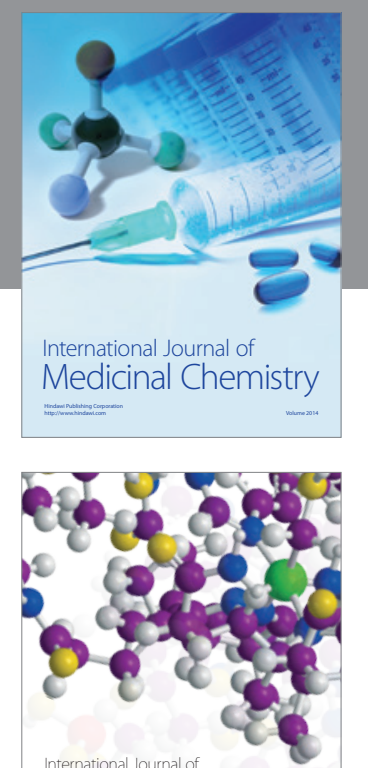

\section{Carbohydrate} Chemistry

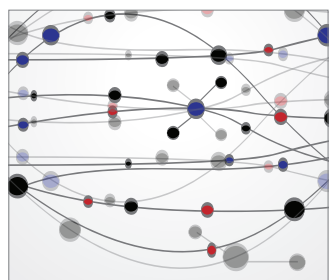

The Scientific World Journal
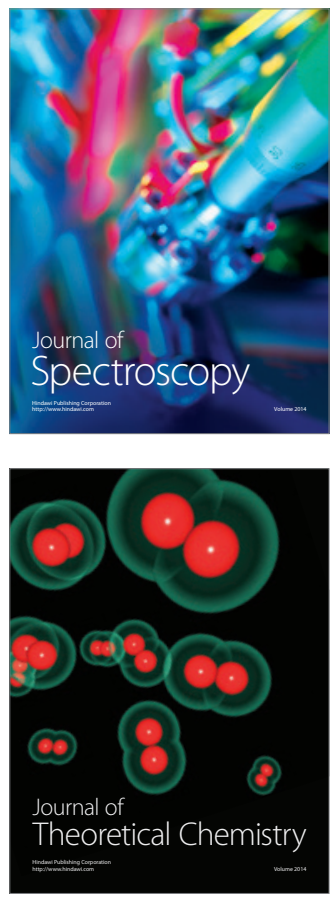
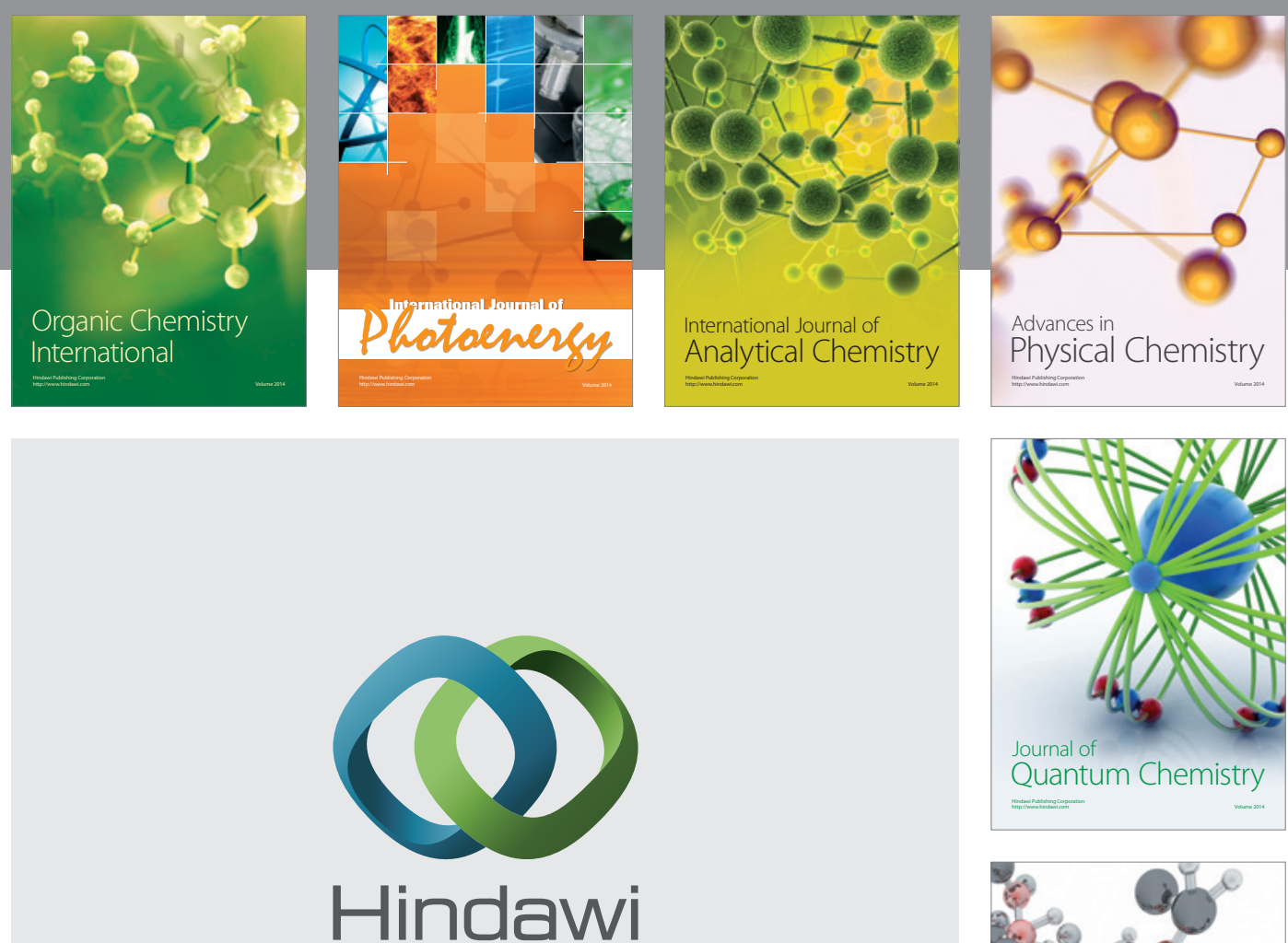

Submit your manuscripts at

http://www.hindawi.com

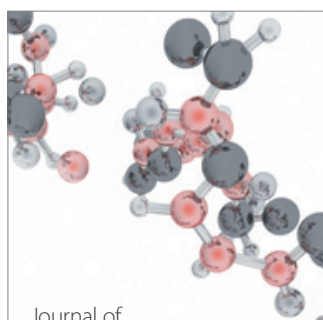

Analytical Methods

in Chemistry

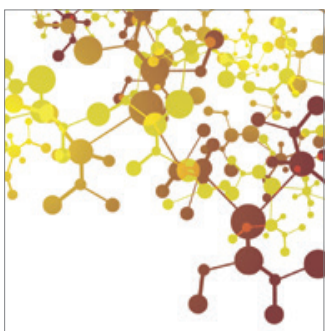

Journal of

Applied Chemistry

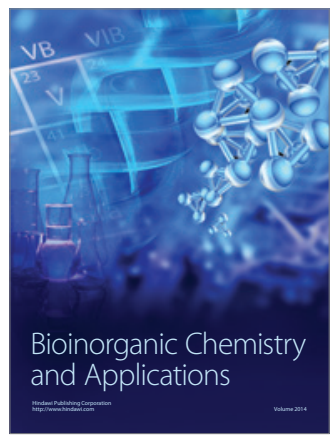

Inorganic Chemistry
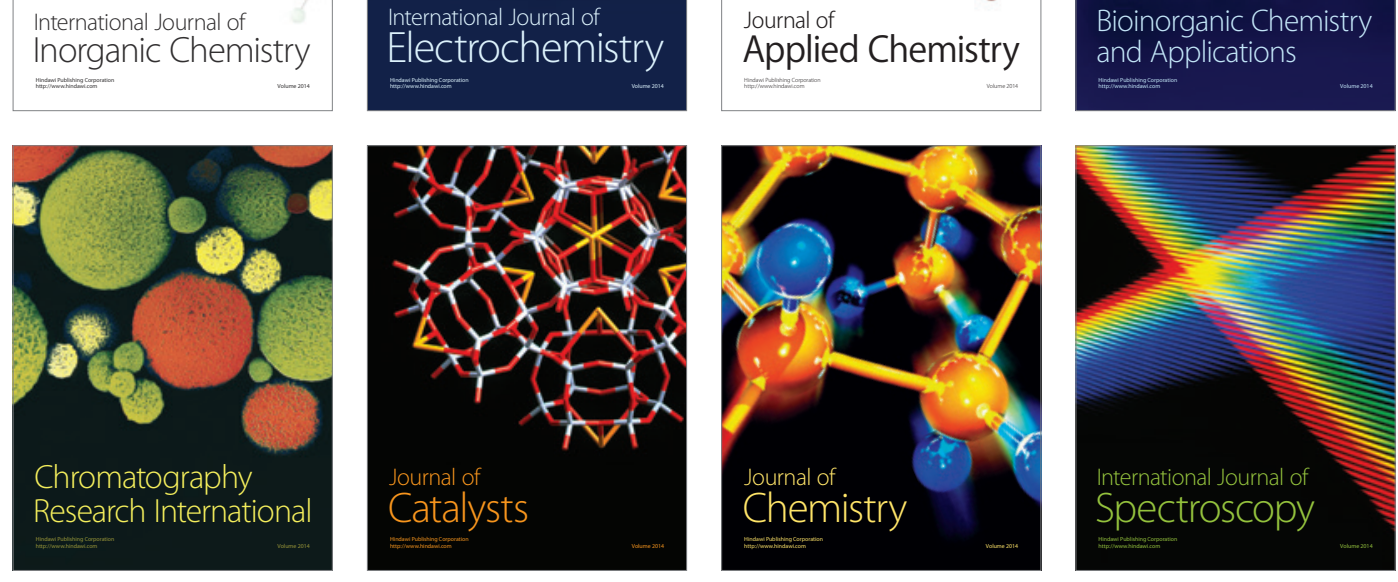